\title{
Model Based on the Constructive Theory to Reduce Mathematics Anxiety for Elementary School Pupils.
}

\author{
Prof/ Hassan Awad Hassan Elgendy \\ Assistant Professor of Obour High Institute for \\ Management \& Informatics, Egypt
}

\begin{abstract}
The recent research aims at knowing the effect of using a model of the constructive theory based on Cognitive Apprenticeship in order to reduce pupils' feeling with anxiety while studying math. The research sample includes 41 students at primary five studying at AL Gawharey primary school belonging to west Tanta educational department during the $1^{\text {st }}$ term of the year 2019-2020. The quasi experimental method is used before and after the application. The aforementioned model is applied via a teacher's guide prepared by the researcher besides making a 23statement scale to reduce math anxiety. These statements are distributed to 5 axes; each of them represents a situation having 2 options: positive and negative. Results show differences with statistical differences at level of $\leq$ 0.05. Consequently, that shows a statistically significant difference between means of pupils' grades enrolled in the experimental group at the favor of the post application. T-value mounts 18,116 which is statistically significant, whereas freedom degree mounts (40).
\end{abstract}

Keywords: Constructive Theory - Cognitive Apprenticeship - Reducing Math Anxiety - Primary Stage.

\section{Introduction}

Looking at teachers as they get knowledge through understanding their experience, Cognitive Apprenticeship is derived from the constructive theory; so teachers are not passive receptors but they are active ones looking for content. Cognitive Apprenticeship methods are applied to overcome problem of acquiring knowledge besides enabling teachers to get rid of discouragement of gaining knowledge by arousing intellectual skills and making learning process clear for both teachers and learners [1].
In addition, cognitive learning helps connect theoretical and practical learning; which enables teachers to solve problems and become knowledgeable guides [2]. The theoretical history of the origins of Cognitive Apprenticeship is distilled into four useful principles, including conventional apprenticeship as a means of active learning. Apprenticeship requires a group of beginner students who help one another explore new knowledge fields [3]. At this point, a teacher is supposed to be more skillful than students and fully aware of the intended activity. Cognitive Apprenticeship is inspired by Traditional one 
and able to make a social context giving learners many chances to observe teachers' performance [4]. Cognitive Apprenticeship strategy can be a prospective for instruction design or can be used as a learning technique by which students learn guidance from teachers or experts. The so-called directed participation helps pupils to do difficult tasks individually which means learning by benefiting from the practical experience of an expert teacher [5]. The first ones to use the term "Cognitive Apprenticeship " derived from " Traditional apprenticeship" related to doing crafts in which a person practises the craft under the supervision of an expert who observes the apprentice's movements step by step and that continues gradually until making students able to do these skills [6]. In order to apply the term "apprenticeship" "on" knowledge, there are four steps to be followed: making tasks clear for pupils, making abstract contexts to force students to understand their work, and differentiating situations to make students understand what they learn teaching methods into modeling, practice, training, contemplation, expressing and exploration[7].

Despite the rapid importance of math nowadays and developments which math methodologies witness, many students and their parents do not only feel anxious towards math, but they also hate it. Educationalists see that feeling anxious during studying math is caused by various reasons: unpleasant school experience, bad of treatment of teachers towards students who face difficulties in learning math, students are afraid of math's qualities such as quickness, accuracy and proficiency or not using adequate strategies while teaching math [8]. Students at primary schools suffer from a constant emotion while doing mathematical sums and that is called "Math Anxiety" which is existed as a reaction towards math. While doing or facing mathematical problems, pupils generate symptoms of fear, freezing limbs OD over sweating [9]. To use Math phobia, argues that students are described by math phobia when they avoid doing math sums which they hate and feel anxious towards them besides considering math a difficult and mysterious puzzle [10] Introduce a set of recommendations which help teachers reduce math anxiety including knowing and acquiring different ways of learning, making good exams, designing positive exercises, feed backing students' responses and making it clear for all that it is natural to make a mistake. and it is important for teachers to help students to think instead of memorizing. [11]

\section{Methodology}

$>$ The recent research contributes to presenting a model of Cognitive Apprenticeship based on the constructive theory for math teachers; the thing which enables them to develop more effective strategies than the traditional ones and enriches the educational process in general and reduces math anxiety in particular.

$>$ The recent research uses the quasi experimental method via measuring the effect of using the Cognitive Apprenticeship model which is based on the constructive theory to reduce math anxiety for primary students.

$>$ The model cares with stages of the constructive learning coinciding with stages of the Cognitive Apprenticeship which are blended in one model to make harmony between the suggested model and the constructive theory as a methodological base for making the model which is shown in the next shape:

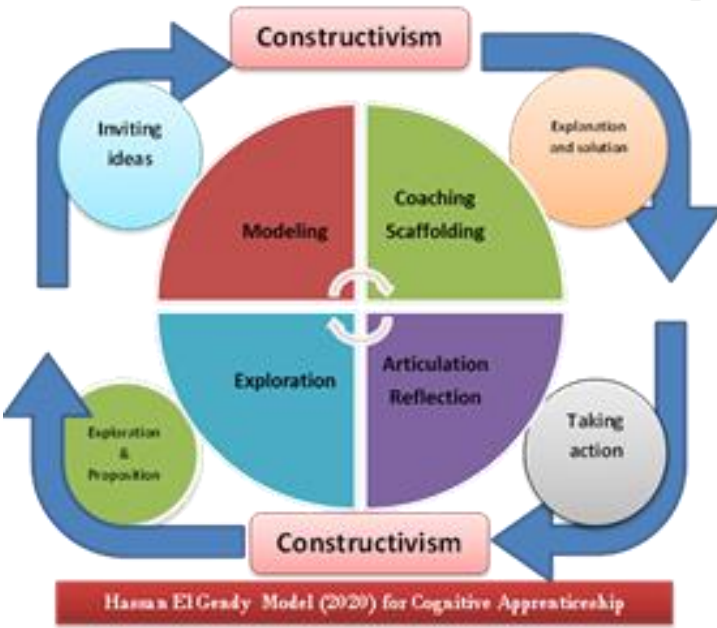

Figure (1) Hassan El Gendy Model for Cognitive Apprenticeship (2020)

The research sample includes 41 students at primary five studying at $\mathbf{A L}$ Gawharey 
a primary school belonging to west Tanta educational department during the $1^{\text {st }}$ term of the year 2019-2020.

$>$ Search implement is a scale to measure math anxiety which is represented by 23 statements distributed into 5 axes: anxiety related to the math book, the teacher, the class, the test and life experiences related to math. Content validity of the measure is verified by a group of experts. The researcher redid the test after two - week interval to test the consistency of it.

\section{Result}

(Spss) program is used to calculate t-test to compare means marks of the pre and post application of the experimental group to measure math anxiety. The following table shows these results: to determine the highest limit for that cell as shown in the following Table:-

Table (1) t-test results to compare means of the pre and post application of experimental group marks in the math anxiety scale "paired samples statistics"

\begin{tabular}{|c|c|c|c|c|c|c|}
\hline Anxiety & Mean & N & $\begin{array}{c}\text { Std. } \\
\text { Deviation }\end{array}$ & t & Df & $\begin{array}{c}\text { Sig. (2- } \\
\text { tailed) }\end{array}$ \\
\cline { 1 - 5 } Pre-test & 18.41 & 41 & 1.18 & 18. & 40 & .000 \\
\cline { 1 - 4 } Post -test & 12.58 & 41 & 1.92 & 11 & & \\
\hline
\end{tabular}

The previous table shows that $\mathrm{t}$-value is $\leq 0.05$. That is a significant difference at the favor of the post application; the thing which proves that there are statistically significant differences between means of pre and post application marks of the experimental group at favor of the post application. $\mathrm{T}-$ Value of the math anxiety scale is 18.116 and the freedom grade is (40).

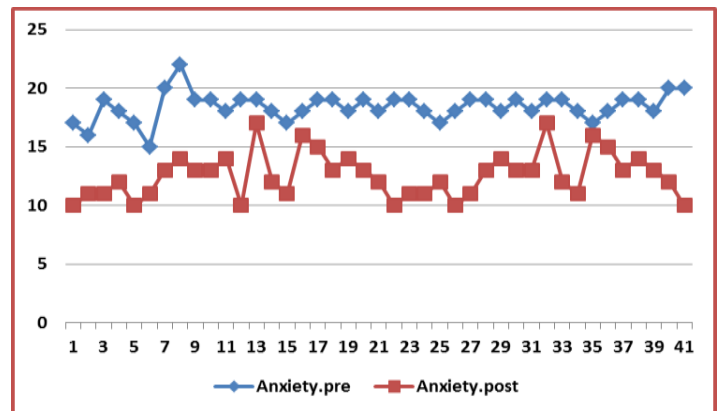

Figure (2) significant differences between means of pre and post application marks of the experimental group

\section{Discussion}

Looking at the previous results, there are statistically significant differences between means of pre and post application marks of the experimental group at the favor of the post application. That is justified by the effects of the constructive theory - based model:

- The suggested Cognitive Apprenticeship model has contributed greatly at the behalf of math teachers and planners; the thing which helps them to develop effective educational strategies enriching the educational process.

- The model is considered an alternative to the traditional ways of teaching math because it gives interest to practice during the stage of eliciting the mathematical sums in a way that reduces math anxiety.

- Expressing and contemplating stage has contributed greatly to motivate students and reduce their anxiety towards the math book, the teacher and class.

- Exploration stage has contributed to encourage students to generate new and creative ideas..

\section{Recommendations}

Teachers can reduce math anxiety of their students by changing teaching environments , using new techniques, focusing on students' outcomes to reduce feeling with failure, encouraging students to like math and consider it a meaningful subject and giving confidence to students while doing sums. The researcher suggests the following behaviors to reduce math anxiety:

1- Presenting math in an interesting style.

2- Using scientific method.

3- Depending on feedback.

4- Using competitive games during classes.

5- Using cooperative learning.

6- Using inquiry- based technique.

7- Using guided discovery way.

8- Using Ozbel advanced experience model in teaching math. 


\section{References}

[1] Bayoumi, Yasser, Elgendy, Hassan. (2017). The effectiveness of the fish bone- strategy in development of achievement, reasoning skills and solving mathematical problems among elementary school pupils. Journal of Mathematics Education, 20 (6), 110-170. doi: 10.21608 / armin.2017.81638.

[2] Bayoumi, Yasser, Elgendy, Hassan. (2013). The impact of Training on some metacognition Strategies on the Development of the ability to Solve Verbal Mathematics Problem Solving with Fifth Grades and Improve their attitude towards it. Journal of Mathematics Education, 16 (1), 30-103. doi: 10.21608 / armin.2013.82378

[3] Elsayed. Howaida (2019). The interaction between the "directed / free" participatory design pattern through a virtual society according to the cognitive apprenticeship methods and the "dependent / independent" cognitive style and its effect on the development of skills performance and cognitive motivation among students of educational technology, Journal of the College of Education in Educational Sciences, Ain Shams University, 43 (4) ), Pp. 1143--1231.

[4] Salamat, Muhammad (2018). The effect of using cognitive apprenticeships in teaching physics on achievement and development of perceptual skills among secondary school students, Journal of the Association of Arab Universities for Education and Psychology, 16 (2), pp. 133-162.

[5] Rashid, Ali (2016). Teaching Science through Cognitive Apprenticeship Theory, The Eighteenth Scientific Conference: Science Curricula between Egyptian and the International: The Egyptian Society for Scientific Education, pp. 65-76.

[6] Khalil, Ibrahim. (2016). Teaching practices of mathematics teachers for the upper grades of the elementary stage in the components of mathematical strength. Journal of the Message of Education and Psychology, (54), pp. 151-172.
[7] Collins,

A.

(2006).

Cognitive Apprenticeship In R. K. Sawyer (Ed). The Cambridge Handbook of the Learning Sciences (pp. 47-60), New York: Cambridge University Press.

[8] Aziz, Ghefaili, (2003). Cognitive Apprenticeship Technology and the contextualization of Learning Environment, Journal of Education computing \& online learning, Vol (4).

[9] Collins, A. Brown, J, \&Newman, S, (1987). Cognitive Apprenticeship: Teaching the craft of reading writing and mathematics (Technical Report No. 403) Cambridge MA: BBN (pp. 47-60), New York: Laboratories, Centre for the Study of Reading University of IIIinois.

[10] Malick, M,. Katke, M., \& Lyer, S. (2014, December). Carromtutor: A Cognitive Apprenticeship Based Tutor FromCarrom Skills and Strategies, In Technology for Education (T44E), 2014 IEEE sixth International Conference on. IEEE.

[11] Joseph, M furner and Mary L D (2002). Equity for All Students in the New Millennium: Disabling Math Anxiety, Intervention in School and Clini vol .38, No .2. Nov 2002

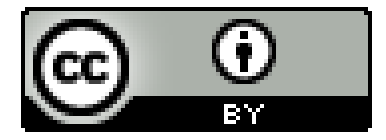

